\title{
Integrating Technology into Teacher Preparation and Practice: A Two-way Mentoring Model
}

\author{
Howard Slepkov \\ Jim Kerr \\ Brock University
}

\begin{abstract}
This article reports on a pilot case study exploring the opportunity for authentic professional development in the use of technology. Self-selected pre-service and inservice teachers were paired so as to reinforce and enhance, firstly, their computer skill development and, secondly, their ability to integrate these same skills into classroom teaching practices. It was proposed that both groups of participants would derive benefit from these pairings. Results overwhelming support this and suggest (a) a model for better preparing teacher candidates to be able to integrate computer skills into classroom programming and (b) a new, perhaps more efficient, method of professional development for busy, dedicated classroom teachers.
\end{abstract}

\section{Rationale}

Information and Communication Technologies (ICT) are among the driving forces behind many of the changes occurring in education (OECD, 2001). Teachers are being asked to incorporate these technologies into their teaching practices (Levin \& Arafeh, 2002; Oblinger, 2003). School boards are spending millions of dollars each year on hardware and software (Dickard, 2003). Research reveals that, despite the money being invested computers are not being used in education (Best, 1999). Emerging studies are finally showing that the use of technology does, indeed, influence student learning positively (Cradler, 2002; Cradler, McNabb, Freeman, \& Burchett, 2002). There does not,

Howard Slepkov is a PhD candidate, a former consultant for the District School Board of Niagara, and currently administrator for Brock's Online Continuing Education Program. Jim Kerr is a professor in the Faculty of Education, deeply involved in efforts to enhance the use of technology by the faculty and students at his home university. 
however, appear to be any major shift towards widespread computer use in the classroom.

In its "Year 2 STaR Report" (1999), the CEO Forum on Education and Technology found that the single greatest deterrent to this lack of computer use is teacher attitude and/or lack of training. While $80 \%$ of schools have Internet connections and the number of schools effectively using technology is almost $25 \%$, only $20 \%$ of teachers reported feeling very well prepared to integrate educational technology into classroom instruction. Cuban, Kirkpatrick, and Peck (2001) reported that access to equipment and software seldom led to widespread teacher and student use. Chadwick (2002), Levin and Arafeh (2002), and Oblinger (2003) all recently confirmed that the obstacle still is the inability of the classroom teacher, for a variety of reasons, to facilitate the use of technology.

Unfortunately, when in-service training is provided to help overcome this obstacle, it is often ineffective (Ertmer, 1999; Maddux, 1998). The question then becomes how to promote and encourage this much-desired educational change?

Recent research has explored the problem of ensuring that graduating pre-service teachers possess the capability to successfully integrate the computer as a tool into their classroom programming (Cherup \& Linklater, 2000; Jayroe, Ball, \& Novinski, 2001; Kamens, 2000). These references suggest that it is not merely enough to make sure that informational technology is being taught as a subject at the pre-service level. There must also be some specific attempt to ensure that the skills being acquired during formal classes are being utilized during practice teaching placements and beyond. Thomas and Cooper (2000), exploring the role of teacher education and the National Educational Technology Standards for JK-12 students of the International Society for Technology in Education, recommend that teacher certification programs include opportunities for students to teach in classrooms where they see integration occurring and include collaborative experiences involving technology-supported instruction.

How is this possible if circumstances result in placement in classrooms where technology is not available or, even more likely, where it isn't being used? If these technology-literate education students are not encouraged by those already in the field to use their technology skills in the delivery of program, then little change is likely to occur. Technological literacy does not easily translate into an ability to know when to use that technology appropriately. If the culture of their school staff room is to leave the technology alone, then these neophyte teachers will be reticent to attempt something new without the support of their more experienced peers on the staff. The STaR 2 report (CEO Forum, 1999) confirms that new teachers entering classrooms currently do not take advantage of the technology that is in the school, but rather adapt to the culture of the 
classroom already in place and leave it alone. Thomas and Cooper (2000) argue that to change this, the training must begin at the teacher-training level.

As pointed out earlier, the same concerns about not integrating technology exist for the regular in-service teacher (Gregoire, Bracewell, \& Laferriere, 1996; Kerr \& Westbrook, 1996). It seems that many are still finding it very difficult to integrate the use of the computer as a tool to enhance the delivery of lessons or to individualize instruction for their students. Often the reasons cited are lack of time, resources, and support to acquire the skills and/or the fear of not having the level of mastery that their students already possess. Workshops and training sessions outside the time frame of the regular school day are increasingly seen as untenable and an intrusion on already burdensome workloads. In-service that requires secondment is expensive for boards of education and once again puts a strain on overtaxed personnel and resources. Alternative learning approaches, including the teaming of teachers in reciprocal teaching, peer-mentor, and tutor-tutee relationships can be effective (Rademacher, Tyler-Wood, Doclar, \& Pemberton, 2001). Vannatta and Beyerbach (2000) suggest that an additional benefit of such pairing is that it leads not only to greater computer competency, but also a deeper understanding of how to integrate the computer into the regular teaching program. Karsten and Roth (1998) emphasized this situational component of computer use in the classroom as impacting on the participants' perceived sense of self-efficacy and therefore heightened the likelihood of further use in a similar environment.

These cited lines of research suggest that both pre-service and inservice teachers can be encouraged, through the appropriate professional development opportunities, to acquire the skills necessary to integrate technology into classroom programming. The next logical step is to consider ways in which such opportunities for professional development might be structured to the advantage of both groups of teachers at the same time. Hargreaves and Fullan (2000) point out that a paradigm shift is occurring in how new teachers should be seen as they enter the profession and it is in this paradigm shift that the solution to this question might be found. Whereas in the past, new teachers were seen as relatively unskilled and in need of support by the system, we should now see them as possessing competencies from which those already in the classroom could benefit. We know that classroom culture changes slowly. Might it not be possible to use these new teachers and their skills to speed up the use of technology by providing them with opportunities to mentor those relatively unskilled in the use of technology? Such mentoring would be seen as a positive approach for enhancing technology skills and efficacy with integrating technology while confronting new teaching challenges, at one and the same time. Franklin, Turner, Kariuki, 
and Duran (2001) found that such an approach definitely overcomes barriers to technology integration in the university environment. Might it not also work well in the JK-12 classroom?

Further evidence of the validity of this approach comes from the work of Dickenson, McBride, Lamb-Milligan, and Nichols (2003) and Harris and Grandgenett (2002). They report on authentic professional development by classroom teachers during the course of conducting regular classes. When this happens, teachers construct their own meaning and learn new skills as they reflect on their daily classroom activities. Kolb (1984) identifies this as experiential learning, following in the school of Vygotsky (1978). Guskey (2000) has suggested this is connecting practices with results. This, we posit, would be the result of pairing pre-service and in-service teachers for the enhancement of technology skill development and integration.

We believe that there is a need for a research study that would explore the potential of the concept of mentoring posited by Hargreaves and Fullan (2000) and Guskey's (2000) concept of connecting practices with results around the use of technology in classroom teaching. As outcomes of such a study, we would hope to find that:

- Teachers would develop strategies to determine how, when, and why to integrate technology into their program based upon the current Ontario Curriculum expectations;

- The comfort and efficacy of practicing teachers, as well as teacher candidates, when using technology in the classroom, would be enhanced;

- Both pre-service and in-service teachers would acknowledge the contribution of each other to these outcomes, and

- This might contribute to the emergence of a culture of change in individual schools around the use of technology.

It was to explore the feasibility of such a study that the pilot project reported herein was conducted.

\section{Procedure}

Support for this conceptual framework was first solicited from the studentteacher advisors in the Department of Education at a mid-sized Southern Ontario university. Once this was granted, all the enrolled pre-service students were 
given the details of the program in the form of a flyer and a brief explanation in class. Those teacher candidates who were interested in the project were encouraged to volunteer themselves as subjects. There were 24 students who expressed such an interest, if a suitable school to receive them could be found. Principals in the schools of the local public school board were similarly invited to volunteer to participate in the project. Some one-quarter of the principals (28) indicated a willingness to participate, after having sought and gained the approval of the classroom teachers who would work with these students. From this group, sites were chosen based upon the requests of the students for placement through their faculty advisors. Students had to agree to practiceteach in those specific schools. In addition, the grades and the subjects to be taught had to be a fit for both pre- and in-service teachers.

Two groups of self-selected participants, therefore, became the focus of this study. The first were the pre-service students. They voluntarily identified themselves as possessing a higher than average level of computer expertise and literacy or being desirous of acquiring those skills. The second were classroom teachers who, as indicated, first volunteered to accept students for a practice-teaching block placement and, second, considered themselves similarly expert and computer literate or, on the other hand, considered themselves computer illiterates but were anxious to develop their skills. Because it was necessary to ensure a match in the schools prior to inclusion in the study, permission forms were only signed after the successful placement was made. Once paired, they were expected to use the technology in their practice-teaching lessons in some way. They were asked to identify an area of ICT which both felt could benefit from collaboration. The assumption was that each dyad needed a focus for their collaboration and choosing one area upon which to focus would better facilitate growth. The researchers assumed that, following the teaching block's completion, not only would participants rate themselves as higher in that one specific area, but that there would be generalized growth over all the competency categories. It was the responsibility of the faculty support staff and field workers to ensure that lesson plans reflected this specific outcome.

While this was seen primarily as a qualitative multi-site case study (Yin, 1994), in order to adequately triangulate the data and provide some evidence of reliability and validity, baseline data of a quantitative nature were collected. One of the assumptions of the researchers was that both students and teachers would enhance their competency levels in ICT skills. It was agreed that some sort of rating scale had to be found to use as a measurement tool. A suitable tool was found on the Internet at the International Society for Technological Education (ISTE) web site. The identified ISTE Foundation Standards were the 
result of a partnership between ISTE and the National Council for Accreditation of Teacher Education (NCATE). The standards represent for them a stable and quantifiable definition of what specific ICT skills new teachers should have as they enter the profession $(1998,2000)$. It was agreed that the authors would adapt this tool, having been given permission by one of its authors.

The Recommended Foundation Competencies in Technology checklist was given to the pre-service teachers at a meeting at the university. The purpose of this meeting was to present the expectations and methodology of the project. The same form was administered at the end of their teaching block. A meeting for the same purposes was called for all the identified in-service teachers. The second copy of the form was distributed to the associate teachers by mail after the teaching block was completed.

The 61 competencies in the rating scale used in this study were divided into nine categories as follows:

1.1 Basic Computer/Technology Operations \& Concepts

1.2 Personal \& Professional Use of Technology

1.3 Application of Technology in Instruction

2.1 Social, Ethical, \& Human Issues

2.2 Productivity Tools

2.3 Telecommunications \& Information Access

2.4 Research, Problem Solving, \& Product Development

3.1 Teaching Methodology

3.2 Hardware, Software Selection, Installation, \& Maintenance.

On each of the competencies, all respondents were asked to assess themselves as being at one of four levels - Entry (Teachers Learning to Use Technology), Adoption (Teachers Use Technology to Support Traditional Instruction), Adaptation (Technology Used to Enrich Curriculum), and Appropriation (Technology is Integrated, Used for its Unique Capabilities). To arrive at a single numerical value that could be used to assess change over time, the scoring of the competencies checklist was done through a simple assignment of a value (1 for Entry through 4 for Appropriation) to each of the possible descriptors. A total for each category was calculated as well as a percentage figure representing how far below the ideal (Appropriation) on all competencies, combined, the respondent perceived himself or herself to be.

Following the meetings with the two groups of participants, phone calls were made to those individual classroom teachers unable to make the whole group sessions. Individual briefings were held as well for those 
students who missed their whole group session. Visits were paid to each of the sites during the four-week teaching block and time was found to interview each of the pre-service candidates and their associates separately. These interviews took the form of informal discussions to elicit impressions and subjective feedback on the success of the placements, the pairings, and how they used the technology. All of these interactions were also opportunities to gather informal data on the participants and feedback concerning their attitudes and feelings towards the pre-service program and the use of technology in teaching.

\section{Observations and Findings}

Both the pre-service students and their designated associate teachers were eager to become involved with the project. They both viewed this project as a way to gain experience with technology in an educational setting by collaborating with others who had similar interests or superior expertise. They wanted, even welcomed, the chance to work with the technology in just such an environment. Some of the students also verbalized an expectation that participation in such a project might have positive effects on their future employment possibilities.

Teachers in the field perceived the project as a vehicle to advance their knowledge of technological applications in the classroom by working with pre-service teachers who might have a higher level of expertise with the technology. Some also saw this as an opportunity to convey some of the ideas and skills that they had developed over the years as their charges advanced their knowledge of the teaching environment.

Principals were keen to volunteer their schools and nominate associates to become involved. They were intrigued by the possibilities inherent in the situation. They wanted to provide their staff member with an opportunity to become more computer-literate and technologically competent.

During the four-week teaching block, visits were paid to each of the sites where pre-service student and associate teacher pairings were situated. Informal interviews were conducted with both individuals to elicit feedback on the process and establish whether any further intervention was required or any additional resources needed in order to facilitate program planning. At the conclusion of these interviews, the comments made in discussion were grouped according to similarity of statement and the number of responses tabulated. Table 1 summarizes that information. 
Table 1

Comments from Participants

Comments

Frequency of Occurrence

\begin{tabular}{|c|c|}
\hline $\begin{array}{l}\text { I learned many new things about technology } \Omega \text { gained } \\
\text { experience with the technology. }\end{array}$ & 15 \\
\hline $\begin{array}{l}\text { The process of mentoring was very worthwhile./The } \\
\text { mentoring process was very good. }\end{array}$ & 14 \\
\hline $\begin{array}{l}\text { I made much progress with my skills./My competency } \\
\text { level has significantly improved. }\end{array}$ & 14 \\
\hline I learned a lot from my partner. & 13 \\
\hline $\begin{array}{l}\text { Technical problems (scheduling, hardware malfunctioning, } \\
\text { Internet access down) prevented the successful completion } \\
\text { of our plans/expectations/outcomes. }\end{array}$ & 8 \\
\hline $\begin{array}{l}\text { We found areas to collaborate on quite easily } / \text { It was easy } \\
\text { to identify an area of mutual interest to work at. }\end{array}$ & 8 \\
\hline I learned a lot about how to teach using technology. & 8 \\
\hline $\begin{array}{l}\text { I learned a lot about how to integrate technology into my } \\
\text { program planning }\end{array}$ & 8 \\
\hline $\begin{array}{l}\text { I put the technology front and centre as part of my program } \\
\text { planning because it was expected of me. }\end{array}$ & 6 \\
\hline $\begin{array}{l}\text { My fear level in terms of using the technology in front of } \\
\text { group of students has been significantly lowered. }\end{array}$ & 6 \\
\hline $\begin{array}{l}\text { I could have used/enjoyed/profited from more time with } \\
\text { my partner. }\end{array}$ & 5 \\
\hline My student/1 was a resource for the entire staff. & 5 \\
\hline I could have used much more time. & 5 \\
\hline $\begin{array}{l}\text { I gained a new perspective on the reality of the technology } \\
\text { in a school setting. }\end{array}$ & 3 \\
\hline $\begin{array}{l}\text { I learned more about the role of technology in the } \\
\text { achievement of specific curriculum expectations. }\end{array}$ & 3 \\
\hline $\begin{array}{l}\text { I could have used more specific guidelines for this entire } \\
\text { process. }\end{array}$ & 3 \\
\hline $\begin{array}{l}\text { I learned very little or nothing as a result of this process. I } \\
\text { experienced no growth in my skill level as a result of this } \\
\text { process. }\end{array}$ & 2 \\
\hline $\begin{array}{l}\text { I had more free time to work with students as a result of } \\
\text { this process. }\end{array}$ & 2 \\
\hline
\end{tabular}

As can be seen from Table 1, the subjective feedback from the respondents in this study reinforces the original assumption of success. This pilot study was only exploring the proposition that there would be growth in 
comfort and competency with technology integrated into classroom practices as a result of this methodology. There were no specific expectations of growth in one domain or another. As the intent of the pilot project was to test the experimental design, it was not considered necessary for the purpose of the research to draw a distinction between comments from teachers or students. Repeatedly, individuals from both groups commented on how much they were enjoying the partnership, how much they were learning, and how much more competent they felt about the technology and its use in the classroom. One teacher even suggested that as a result of her experience, she would not hesitate to try and integrate ICT skills from the outset in her first year of teaching. She revealed that, previously, when she reflected upon the future and the use of the computer, she was sure she would be unable to manage teaching and the technology at the same time. However, her experiences within this study led her to change her mind and lowered her fear level considerably. Invariably, comments were continuously made in passing about reducing fear in both the pre-service and the veteran teachers.

Going from school to school, the researchers continually found the associates enthusiastic and exuberant about the project. What was not entirely surprising was the fact that the younger pre-service students became a resource for the whole staff. In two cases, specifically, a process had been worked out whereby the staff as a whole was working individually with the pre-service candidate to enhance competencies in one area or another. In one school, it was with presentation software, in another it was in the area of spreadsheets, in a third it was the Internet. When the scores were tabulated category by category, the data revealed that both groups did, in fact, experience growth in their perceived competency levels over all the criteria. Using the same standard of measurement for perceived competency levels, associate teachers self-rated their own growth by $6 \%$ over all and pre-service student teachers saw their competency levels grow by $19 \%$.

While it would be very interesting to analyze the results by category and perhaps speculate on why growth was greater in some categories than in others, this particular study was meant to focus on general perceived competency. The classroom teachers in this study did not grow as much as was expected overall. This might be due to the fact that most of them were selected by their principals because of their leadership and proven ability in ICT skills. The exact opposite was revealed by the results for the pre-service teachers, who gained exactly what they were looking for - mentorship from individuals who knew what they were doing with the technology. Growth was measured in each category and in the overall general summary measurement as well. This result supported the comments elicited during the interviews. 


\section{Discussion}

This project began with the assumption that there would be benefits in matching pre-service students and associate teachers and placing the development of ICT competencies in the forefront of their planning. The former would perceive themselves to be technologically competent and want to put into practice these skills in their teaching blocks. The latter would be eager to either further their skills or mentor a student toward similar competence. The results of these pairings reported above, while positive, should be viewed in light of several factors.

For example, the survey forms were not completed at the same time, in the same circumstances, by both groups or even by all individuals in each group. Some participants made their choices and returned them immediately. Others needed to be repeatedly reminded until they were returned. In the end, only 8 of 15 pre-service students completed and returned both the pre and post surveys within the time constraints of the project. This does not, however, detract from the significance of the personal reflections. The responses received in written format can be seen as an opportunity to provide triangulation of the data (Yin, 1994).

Often, respondents did not fully understand the terminology of the descriptors on the measurement instrument. They were also reluctant to rate themselves at the higher end of the rating scale because they felt that, next to a consultant or technical support person, they must be much lower in their skills. Both teachers and students had a tendency to under-appraise themselves in terms of their general levels of technical ability. This did not come out in the personal interviews, however, where teachers and pre-service candidates were far more honest about their abilities or lack thereof.

Although the original intent was for each pair to identify a specific area in which to develop competency, at no time were they asked to follow that up and identify the area they had agreed upon. It would have been much better for interpretation and generalization of the findings if this had been done. This would have allowed the results for that one area to be compared to that of all other areas and ICT skills in general.

Since this was a project that evolved over time and solidified its main outlines, the process of matching up pre-service students and associate placements was mostly happenstance. No criteria were defined to set parameters for the working environment of the teaching block. The matches made between students and their placements were found at all grade levels and

therefore included rotary and non-rotary teaching situations. Indeed, one of the matches was found in a secondary school and because of its rotary nature, the 
expectations of both the associate and the student could not be easily compared to a situation in a primary classroom.

Many of the results were significantly altered by problems with the technology itself. In several situations, major work being done on the networks and their infrastructure prevented access on a continuing basis by all concerned. In other situations, the demands upon the networked machines made it necessary for planning to take into account shared access rather than access upon demand. This finding is in keeping with that of Kamens (2000) who also validates the concept of collaboration as a way to mitigate the frustrations caused by the problems with access to the hardware.

This project documents the impact on practicing teachers and preservice students who participated in a program that was designed to increase their focus on the use of information technology in their teaching practices. It was found that an average of four weeks of focusing on the use of technology in classroom practice resulted in increases in many of the perceived skill levels. In addition, both pre-service candidates and associate host teachers reported that they enjoyed the experience and the chance to pay particular attention to the technology.

As pointed out above, this project was very successful and fulfilled most of the expectations of the researchers. However, this must be seen as a pilot study only. The authors look forward to continuing the process and perhaps even broadening it. In so doing, certain aspects of the project need to be refined. These include the following:

- The survey instrument needs to be administered to everyone at the same time and collected immediately, both at the beginning and at the end of the teaching block. In addition, there needs to be a second instrument (Johnson \& Christensen, 2000), one that provides structure and flow during the face-to-face interviews conducted at the schools during the actual teaching block. Gilmore (1995), reporting on a study that focused on the teaching of and integration of computer competencies with teachers in New Zealand, used such a questionnaire to measure the success of her program rather than attempting to encode generalized interview data.

- The last teaching block in the one-year teacher-training program has been identified in several studies as the ideal time to include the integration of technology. Dawson and Norris (2000) used a mentorship approach similar to 
that used in this study. Pre-service students were instructed in technology competencies as one of their courses in their program, were expected to use the technology in the projects they were assigned, and then they were expected, as a final step, to go into schools and implement these same skills in a practice-teaching environment. The progression from learning the competencies to using them for oneself and then having an expectation to apply those skills in a new environment makes logical and cognitive sense.

\section{Conclusions}

This pilot study was meant to explore the feasibility of a co-mentoring program pairing pre-service and associate teachers. These dyads were matched up in such a way that one or the other of the pair would serve to enhance the technology skills of both. This took place at the same time when they would be learning together to become more comfortable with the integration of technology into classroom programming. After a very preliminary analysis of the results of such pairings it was found that, at least with these participants, more was learned about integration of technology. Both pre-service and associate teachers became more comfortable with the use of technology as part of their classroom. Both members of the dyad frequently acknowledged the contribution of each partner in making small changes in their teaching practices, now and in the future. The researchers felt that, subject to the limitations identified above, their pilot was a success and merits further study.

Teachers in classrooms around the world are struggling to keep up with the changes in technology, especially since their students may be more computer-literate than they are (Hird, Levin, \& Arafeh, 2002). They are grappling with the problem of how to deliver effective programs based upon the curriculum as it is centrally defined, while also finding the time to integrate skills that are expected to be included by parents and administrators, required for success in the future, and which are in a constant state of flux. Professional educators work in an environment where the expectations of the curriculum are not matched by the level or state of the technology it depends upon for integration (Maddux, 2002). Finally, they are trying to implement new methods of program delivery, assessment and evaluation, while it is expected that they become professionally developed in Information and Communication Technologies, often on their own time or, at best, during all-too-short seconded professional development opportunities. All of these pressures have a tremendous impact on their day-to-day functioning and, as has been pointed 
out by Hargreaves (1994), teachers are unable to effectively cope in this situation and so feel isolated, alone, and increasingly ineffectual.

Pre-service teachers are coming to the Colleges of Education having many of the ICT competencies in place but unable to or unsure of how to apply them to their developing teaching repertoires. They are aware of the numerous changes in the world of technology and expect to be able to use these technologies in their classrooms. The expectations of practice teaching do not purposefully include technology, so newly hired teachers begin to become acculturated to an environment that does not place high value on the use of the hardware and software already in the schools (Brent, Brawner, \& Van Dyk, 2002). As Borko and Shavelson (1990) point out, novice teachers begin with little experience in how to structure their day, how to put together effective lessons, and how to structure a series of learning experiences. As they reflect on what works and what doesn't work, they develop a method of planning that works for them. Over time, they become experts in accommodating themselves to this new environment, the culture of the school, and once they find a comfort level, change becomes more difficult to make. If we are to ensure that the integration of computer skills is bundled together with other teaching practices in newly graduated teachers, we must not overlook the role of the overall school culture into which these new professionals become settled (Barth, 1990, 2001). Schofield (1995) reinforces this view, commenting that computers become part of the social reality of the school. He goes further to posit that their use will bring about other structural changes in the school environment and the teaching practices of its staff.

Anything that can bring ongoing professional development right into the classroom of a practicing teacher will significantly change the teaching practices of that teacher (Lambert, Collay, Dietz, Kent, \& Richert, 1996; Thomas \& Cooper, 2000). Anything that can be done to ensure that teachers-in-training are provided with opportunities to integrate ICT into their practice-teaching environments will significantly increase the likelihood that they will use these same skills when in a classroom of their own.

Mentorship can be a two-way street in classrooms, and by purposefully including technology, provision is made for in-service for practicing teachers in ICT that is just in time and on demand. There can be support for them for risk-taking because they are involved in mentoring students who are in a learning mode. There are chances for pre-service teachers to use their ICT skills while learning how to apply them to their prospective 
careers. There is modeling for both groups on how to integrate technology in useful and productive ways. The technology then becomes a seamless part of the educational endeavour for staff, both newly trained and experienced and becomes, in the words of Kerr (1991), a lever and a fulcrum in the service of educational change as reflected in teachers' thoughts and practices.

\section{References}

Barth, R. (1990). Improving schools from within: Teachers, parents, and principals can make a difference. San Francisco: Jossey-Bass.

Barth, R. (2001). Learning by heart. San Francisco: Jossey-Bass.

Best, A. (Ed.) (1999). Information technology underused in teacher education new study reports. ISTE Update, 11.

Borko, H., \& Shavelson, R. J. (1990). Teacher decision-making. In B. F. Jones, \& L. Idol (Eds.), Dimensions of thinking and cognitive instruction (p. 311-345). Hillsdale, NJ: Lawrence Erlbaum Associates.

Brent, R., Brawner, C. E., \& Van Dyk, P. (2002). Factors influencing student teachers' use of technology. Journal of Computing in Teacher Education. 19(2), 40-46.

CEO Forum (1999). Year 2 STaR Report. Retrieved April, 2000 from http://www.school.za/edict/STaR/contents.htm

Chadwick, C. (2002). Why computers are failing in the education of our children. Educational Technology, 42(5), 35-40.

Cherup, S., \& Linklater, L. (2000). Integrating technology into preservice education: A model implemented at one small liberal arts college. Journal of Computing in Teacher Education, 16(3), 18-22.

Cradler, J. (2002). Finding research-based information about technology in teaching and learning. Learning \& Leading with Technology, 29(7), 46-49.

Cradler, J., McNabb, M., Freeman, M., \& Burchett, R. (2002). How does technology influence student learning? Learning \& Leading with Technology, 29(8), 46-56.

Cuban, L., Kirkpatrick, H., \& Peck, C. (2001). High access and low use of technologies in high school classrooms: Explaining an apparent paradox. American Educational Research Journal, 38(4), 813-834.

Dawson, K., \& Norris, A. (2000). Preservice teachers' experiences in a k-12/ university technology-based field initiative: Benefits, facilitators, constraints, and implications for teacher educators. Journal of Computing in Teacher Education, 17(1), 4-12. 
Dickard, N. (Ed.). (2003). The sustainability challenge: Taking edtech to the next level. Washington, DC: The Benton Foundation. Also available from http://www.benton.org/publibrary/sustainability/sus_challenge.htm

Dickenson, G., McBride, J., Lamb-Milligan, J., \& Nichols, J. (2003). Delivering authentic staff development. Education, 124(1), 163-169.

Ertmer, P. A. (1999). Addressing first- and second-order barriers to change: Strategies for technology integration. Educational Technology Research \& Development, 47(4), 47-61.

Franklin, T., Turner, S., Kariuki, M., \& Duran, M. (2001). Mentoring overcomes barriers to technology integration. In Journal of Computing in Teacher Education, 18(1), 26-30.

Gilmore, A. M. (1995). Turning teachers on to computers: Evaluation of a teacher development program. Journal of Research on Computing in Education, 27(3), 251-269.

Gregoire, R., Bracewell, R., \& Laferriere, T. (1996). The contribution of new technologies to learning and teaching in elementary and secondary schools. SchoolNet. Retrieved November 15, 2004 from http://www.fse.ulaval.ca/fac/tact/fr/html/apport/impact $96 . h t m l$.

Guskey, R. R. (2000). Evaluating staff development. Thousand Oaks, CA: Corwin Press.

Hargreaves, A. (1994). Changing teachers, changing times: Teachers' work and culture in the postmodern age. Toronto, ON: OISE Press.

Hargreaves, A., \& Fullan, M. G. (2000). Mentoring in the new millennium. Theory Into Practice, 39(1), 50-56.

Harris, J., \& Grandgenett, N. (2002). Teachers' authentic e-learning. Learning \& Leading with Technology, 30(3), 54-58.

International Society for Technology in Education (2000). National educational technology standards for students: Connecting curriculum and technology. Washington, DC: Author.

ISTE Accreditation and Standards Committee. National standards for technology in teacher preparation. Retrieved (1998) from http://www.iste.org/standards/.

Jayroe, T. B., Ball, K. C., \& Novinski, M. R. (2001). Professional development partnerships integrating educational technology. Journal of Computing in Teacher Education, 18(1), 12-18.

Johnson, B., \& Christensen, L. (2000). Educational research: Qualitative and quantitative approaches. Boston, MA: Allyn \& Bacon.

Kamens, M. W. (2000). Technology in the schools: Perspectives of a collaborative training partnership. Journal of Computing in Teacher Education. 16(2), 26-32. 
Karsten, R., \& Roth, R. M. (1998). The relationship of computer experience and computer self-efficacy to performance in introductory computer literacy courses. Journal of Research on Computing in Education, $31(1), 14-24$.

Kerr, S. (1991). Lever and fulcrum: Educational technology in teachers' thought and practice. Teacher's College Record, 93(1), 114-136.

Kerr, S., \& Westbrook, K. (1996). Technology and the future of schooling. Chicago: NSSE: Distributed by University of Chicago Press.

Kolb, D. A. (1984). Experiential learning: Experience as the source of learning and development. Englewood Cliffs, NJ: Prentice-Hall.

Lambert, L., Collay, M., Dietz, M. E., Kent, K., \& Richert, A. E. (1996). Who will save our schools: Teachers as constructivist leaders. Thousand Oaks, CA: Corwin Press.

Levin, D., \& Arafeh, S. (2002). The digital disconnect: The widening gap between Internet-savvy students and their schools. Retrieved (2002) from http://www.pewinternet.org/reports/pdfs/ PIP_Schools_Internet_Report.pdf.

Maddux, C. D. (1998). Barriers to the successful use of information technology in education. Computers in the Schools, 14(3/4), 5-11.

Maddux, C. D. (2002). Information technology in education: The critical lack of principled leadership. Educational Technology, 42(3), 41-50.

Oblinger, D. (2003, July/August). Boomers \& gen-xers \& millenials: Understanding the new students. Educause, 36-47.

Office of Technology Assessment. (1995). Teachers and technology: Making the connection. Washington, DC: Government Printing Office.

Organization for Economic Cooperation and Development. (2001). Education at a glance: OECD indicators. Paris: OECD Publications.

Rademacher, J., Tyler-Wood, T., Doclar, J., \& Pemberton, J. (2001). Developing learner-centered technology assignments with student teachers. Journal of Computing in Teacher Education, 17(3), $18-25$.

Schofield, J. W. (1995). Computers and classroom culture. New York: Cambridge University Press.

Thomas, J. A., \& Cooper, S. B. (2000). Teaching technology: A new opportunity for pioneers in teacher education. Journal of Computing in Teacher Education, 17(1), 13-19.

Vannatta, R. A., Beyerbach, B. (2000). Facilitating a constructivist vision of technology integration among education faculty and preservice 
teachers. Journal of Research on Computing in Education, 33(2), 132-148.

Vygotsky, L. S. (1978). Mind in society: The development of higher psychological processes. (M. Cole, V. John-Steiner, S. Scribner, \& E. Souberman, Eds. \& Trans.) Cambridge, MA: Harvard University Press.

Yin, R. K. (1994). Case study research: Design and methods. Thousand Oaks, CA: Sage. 